\title{
Pulmonary Gas Trapping in Premature Infants
}

\author{
A. N. Krauss [23] and P. A. M. Auld [24] \\ Department of Pediatrics, Cornell University Medical College, New York, New York, USA
}

\begin{abstract}
Extract
Measurements of thoracic gas volume and functional residual capacity were performed serially from birth on 26 premature infants to determine the presence and time course of gas trapping. Nitrogen washouts were carried out on 16 of these infants and urinary-alveolar nitrogen gradients $\left(\mathrm{uAD}_{\mathrm{N}_{2}}\right)$ were measured in 7 . The infants were divided into two groups, those above and those below $1750 \mathrm{~g}$ birth weight. Trapped gas was documented in both groups, but in the smaller infants the condition persisted for a longer time. The mean thoracic gas volume (TGV) in infants over $1750 \mathrm{~g}$ birth weight was $2.0 \pm 0.7 \mathrm{ml} / \mathrm{cm}$ at birth, with a mean functional residual capacity (FRC) of $1.3 \pm 0.4 \mathrm{ml} / \mathrm{cm}$; by day 9 , the TGV and FRC were $1.5 \pm$ 0.3 and $1.2 \pm 0.2 \mathrm{ml} / \mathrm{cm}$, respectively. Infants under $1750 \mathrm{~g}$ birth weight had a mean TGV of $1.7 \pm 0.2 \mathrm{ml} / \mathrm{cm}$ at birth with an FRC of $0.9 \pm 0.2 \mathrm{ml} / \mathrm{cm}$; by week 2 of life, mean TGV and FRG were $0.9 \pm 0.2$ and $0.8 \pm 0.2 \mathrm{ml} / \mathrm{cm}$, respectively. When gas trapping was present, nitrogen washouts and $u \mathrm{AD}_{\mathrm{N}_{2}}$ indicated that the lung was a single well ventilated space with no evidence of an abnormal distribution of ventilation. This indicated that ventilation of the trapped areas was so small that it could not be measured. The possibility that gas trapping is related to the presence of lung fluid and very compliant airways is considered.
\end{abstract}

\section{Speculation}

Low birth weight infants have been shown to have high airway resistance, compliant airways, and low lung volume. This combination of findings has been associated with airway closure in adults. The possibility arises that a volume of gas is "trapped" with each expiration until airways are sufficiently stiff and remain patent with every breath.

\section{Introduction}

Studies performed to describe the adaptation of the newborn lung to the extrauterine environment have repeatedly shown a fall in thoracic gas volume (TGV) in the days after birth $[4,16]$. This decrease in volume can frequently be noted clinically as a decrease in the size of the chest, especially in smaller premature infants. One explanation for this change is that in the process of expanding the lungs pulmonary gas trapping occurs soon after birth and subsequent disappear- ance of this trapped gas accounts for the fall in TGV. The volume of trapped gas may be determined by comparing values obtained from measurements of TGV and functional residual capacity (FRC). Thoracic gas volume, determined plethysmographically, is a measure of all gas in the lung. This determination may differ from FRC, which measures only gas in alveoli in contact with the airways. A discrepancy in these volumes, where TGV exceeds FRC, is a measure of gas trapped in alveoli and not in free communication with airways [2]. 
This study was carried out to establish the presence of trapped gas in the lungs of premature infants of various birth weights, and to measure serially the amount of gas and duration of entrapment by concurrent determination of TGV and helium FRC. The ventilatory characteristics of premature newborn lungs with gas trapping were studied by nitrogen washout, and ventilation-perfusion relationships by measurement of urinary alveolar nitrogen gradients.

\section{Materials and Methods}

The subjects were 26 infants ranging in weight from 840 to $2500 \mathrm{~g}$ [21]. At the time of study, all were quiet, nondistressed, and 30-60 min postprandial. Serial observations of TGV were made by the plethysmographic method [7] as modified for infants [1]. Tidal volume was measured in the plethysmograph prior to the TGV maneuver. Immediately afterward FRG was measured by a modification of the helium closed circuit rebreathing method of Lewis and others [12]. In this test a Neoprene rubber bag [17] of 25 or $50 \mathrm{~cm}^{3}$ capacity was used. The dead space of the system was either 5 or $7 \mathrm{~cm}^{3}$, depending on the size of the infant. The neck of the bag was clamped with forceps, and the bag was filled with a mixture of $12-14 \%$ helium in oxygen. An aliquot was then removed from the bag for determination of helium concentration, and a measured volume of helium and oxygen approximating the subject's FRC was left for the test. The bag and mask apparatus was placed on the infant's face. When the subject was breathing normally (as indicated by the flutter valve) the clamp was removed from the helium-oxygen bag and the valve was clamped at end-expiration. Rebreathing was continued for $30-60 \mathrm{sec}$ or for at least 40 breaths. If hyperventilation or crying ensued, the test was repeated. At the conclusion of the rebreathing period, the bag was clamped at end-expiration. The volume of gas remaining in the bag was aspirated into a calibrated syringe for measurement of volume, and the helium concentration was determined. A helium catharometer [18] calibrated with 7 and $14 \%$ helium was used. The dead space of the catharometer was minimized so that only $15 \mathrm{ml}$ of gas were required. This volume was always available.

At the conclusion of each test, a small aliquot of gas was reserved for determination of carbon dioxide content as this gas was absorbed before the gas entered the catharometer, and a correction had to be made for the loss of volume due to loss of $\mathrm{CO}_{2}$. The $\mathrm{PCO}_{2}$ of the gas was determined on an ultramicro [19] system, and $\mathrm{CO}_{2}$ content was determined from this. The FRG was calculated by the equation:

$$
\mathrm{FRC}=\frac{\left(V_{i} \times \mathrm{He}_{i}\right)-\left(V_{f} \times \mathrm{He}_{f}\right)}{\mathrm{He}_{f}}
$$

where $V_{i}$ and $V_{f}=$ initial and final bag volume; $\mathrm{He}_{i}$ and $\mathrm{He}_{f}=$ initial and final helium concentration corrected for absorption of $\mathrm{CO}_{2}$. Final volumes were corrected to body temperature, pressure, saturated with water vapor (BTPS). The reported values represent the average of three to five determinations.

Nitrogen washout studies were carried out on 16 of these infants using a nose valve with a dead space of $1.0 \mathrm{ml}$. When the subject was breathing quietly, he was switched from room air to $99.8 \%$ oxygen. Expired gas was sampled just above the expiratory valve, and breath-by-breath $\mathrm{F}_{\mathrm{N}_{2}}$ was recorded with a Nitralyzer [20] and a direct writing polygraph. The washout was continued until the nitrogen in expired gas was $2 \%$ or less. Two or three satisfactory runs were recorded for each subject. The Nitralyzer was calibrated with gas of $2.4,7.8,54.9$, and $78.1 \%$ nitrogen. One percent nitrogen was subtracted from each expired $\mathrm{N}_{2}$ point to correct for nitrogen washout from body stores [14]. Washout curves were then plotted and analyzed by the methods of Fowler, Cornish, and Kety [9] and Briscoe and Cournand [3]. The curve with the most uniform respiratory rate and tidal volume was selected for detailed analysis. In each instance, the results from analysis of one representative curve are presented. The urinary alveolar nitrogen gradient $\left(\mathrm{uAD}_{\mathrm{N}_{2}}\right)$ was determined in seven infants by the methods of Farhi, Edward, and Homma [8] as modified by Krauss and Auld [11]. A periodic check of the accuracy of the method was carried out by determination of the Bunsen coefficient for $\mathrm{N}_{2}$ in distilled water equilibrated with air at $37^{\circ}$. A value of $0.0127 \mathrm{ml} \mathrm{N} / \mathrm{ml}$ water $/$ atm $\mathrm{N}_{2}$ at $37^{\circ}$ was repeatedly obtained $[8,21]$.

\section{Evaluation of the Helium Rebreathing Method}

Using the helium rebreathing method for FRC described above, values within $5-10 \mathrm{ml}$ could be repeatedly determined when care was taken to avoid crying and hyperventilation. The volume of a dummy lung could be accurately determined within $1 \mathrm{ml}$. The usual standard error of the test was $\pm 10 \%$ of FRC. Infants who had apneic pauses during the rebreathing maneuver showed larger variations.

To ensure that adequate mixing between lungs and bag was occurring, experiments were performed prolonging the rebreathing period up to $3 \mathrm{~min}$. No differ- 
Table I. Serial studies of thoracic gas volume (TGV) and functional residual capacity (FRC)

\begin{tabular}{|c|c|c|c|c|c|c|c|c|c|c|c|}
\hline \multirow[b]{2}{*}{ Case } & \multirow{2}{*}{$\begin{array}{c}\text { Birth } \\
\text { weight, } \\
\text { g }\end{array}$} & \multicolumn{3}{|c|}{ At time of study } & \multirow[b]{2}{*}{ TGV, ml } & \multirow{2}{*}{$\begin{array}{l}\mathrm{TGV}, \\
\mathrm{ml} / \mathrm{cm}\end{array}$} & \multirow[b]{2}{*}{ FRC, ml } & \multirow{2}{*}{$\begin{array}{c}\text { FRC, } \\
\mathrm{ml} / \mathrm{cm}\end{array}$} & \multirow{2}{*}{$\begin{array}{c}\text { TGV-FRC, } \\
\mathrm{ml} / \mathrm{cm}\end{array}$} & \multirow{2}{*}{$\begin{array}{c}\text { Tidal } \\
\text { volume, } \\
\mathrm{ml}\end{array}$} & \multirow{2}{*}{$\begin{array}{l}\mathrm{uAD} \mathrm{N}_{\mathrm{N}}, \\
\mathrm{mm} \mathrm{Hg}_{\mathrm{g}}\end{array}$} \\
\hline & & $\begin{array}{c}\text { Weight, } \\
\mathbf{g}\end{array}$ & $\begin{array}{l}\text { Age, } \\
\text { days }\end{array}$ & $\begin{array}{l}\text { Length, } \\
\mathrm{cm}\end{array}$ & & & & & & & \\
\hline 1 & 840 & 840 & $6 \mathrm{hr}$ & 34 & $62 \pm 14^{1}$ & 1.8 & $22 \pm 4$ & 0.6 & 1.2 & & \\
\hline 2 & 794 & $\begin{array}{l}1200 \\
1250\end{array}$ & $\begin{array}{l}35 \\
36\end{array}$ & $\begin{array}{l}35 \\
36\end{array}$ & $58 \pm 12$ & 1.7 & $\begin{array}{l}48 \pm 1 \\
53 \pm 11\end{array}$ & $\begin{array}{l}1.4 \\
1.5\end{array}$ & 0.3 & 12.0 & \\
\hline 3 & 2260 & $\begin{array}{l}2260 \\
2200 \\
2140 \\
2160 \\
2100\end{array}$ & $\begin{array}{l}4 \mathrm{hr} \\
1 \\
4 \\
6 \\
7\end{array}$ & $\begin{array}{l}43 \\
43 \\
43 \\
43 \\
44\end{array}$ & $\begin{array}{r}111 \pm 18 \\
112 \pm 18 \\
114 \pm 17 \\
62 \pm 13 \\
91 \pm 18\end{array}$ & $\begin{array}{l}2.6 \\
2.6 \\
2.7 \\
1.4 \\
2.1\end{array}$ & $\begin{aligned} 113 & \pm 7 \\
72 & \pm 8 \\
72 & \pm 4 \\
71 & \pm 13 \\
70 & \pm 1\end{aligned}$ & $\begin{array}{l}2.6 \\
1.7 \\
1.7 \\
1.7 \\
1.6\end{array}$ & $\begin{array}{r}0.0 \\
0.9 \\
1.0 \\
-0.3 \\
0.5\end{array}$ & $\begin{array}{r}8.0 \\
11.0 \\
7.0 \\
11.0 \\
10.0\end{array}$ & \\
\hline 4 & 1920 & $\begin{array}{l}1920 \\
1900\end{array}$ & $\frac{4}{1} \mathrm{hr}$ & $\begin{array}{l}45 \\
45\end{array}$ & $\begin{array}{l}77 \pm 6 \\
71 \pm 5\end{array}$ & $\begin{array}{l}1.7 \\
1.6\end{array}$ & $\begin{array}{l}40 \pm 3 \\
55 \pm 5\end{array}$ & $\begin{array}{l}0.9 \\
1.2\end{array}$ & $\begin{array}{l}0.8 \\
0.4\end{array}$ & $\begin{array}{r}11.0 \\
7.0\end{array}$ & $\begin{array}{l}3.8 \\
3.0\end{array}$ \\
\hline & & 1790 & 3 & 45 & $55 \pm 10$ & 1.2 & $72 \pm 16$ & 1.6 & -0.4 & 10.0 & \\
\hline 5 & 1830 & $\begin{array}{l}1830 \\
1820\end{array}$ & $\begin{array}{l}1 \\
3\end{array}$ & $\begin{array}{l}40 \\
40\end{array}$ & $53 \pm 8$ & 1.3 & $\begin{array}{l}68 \pm 8 \\
60 \pm 10\end{array}$ & $\begin{array}{l}1.7 \\
1.5\end{array}$ & -0.4 & 9.0 & \\
\hline 6 & 1320 & 1340 & 16 & 41 & $52 \pm 3$ & 1.3 & $31 \pm 3$ & 0.8 & 0.5 & 11.0 & \\
\hline 7 & 1160 & 1160 & $8 \mathrm{hr}$ & 37 & $94 \pm 12$ & 2.5 & $29 \pm 2$ & 0.8 & 1.7 & 5.0 & \\
\hline & & 1080 & 1 & 37 & $93 \pm 8$ & 2.5 & $55 \pm 3$ & 1.5 & 1.0 & 6.0 & \\
\hline & & 1020 & 2 & 37 & $93 \pm 15$ & 2.5 & $37 \pm 6$ & 1.0 & 1.5 & 12.0 & \\
\hline & & 1050 & 4 & 37 & $34 \pm 7$ & 0.9 & $30 \pm 2$ & 0.8 & 0.1 & 8.0 & \\
\hline & & 1060 & 12 & 38 & $42 \pm 3$ & 1.1 & $41 \pm 1$ & 1.1 & 0.0 & 12.0 & \\
\hline 8 & 1030 & 1030 & $4 \mathrm{hr}$ & 34 & $58 \pm 11$ & 1.7 & $30 \pm 10$ & 0.9 & 0.8 & 8.0 & \\
\hline & & $\begin{array}{l}930 \\
940\end{array}$ & $\begin{array}{r}4 \\
18\end{array}$ & $\begin{array}{l}35 \\
39\end{array}$ & & & $\begin{array}{l}33 \pm 1 \\
22 \pm 4\end{array}$ & $\begin{array}{l}0.9 \\
0.6\end{array}$ & & & \\
\hline & & 970 & 19 & 39 & $37 \pm 3$ & 0.9 & $\begin{array}{l}22 \pm 4 \\
18 \pm 2\end{array}$ & $\begin{array}{l}0.0 \\
0.5\end{array}$ & 0.4 & 8.0 & \\
\hline & & 1070 & 33 & 39 & $43 \pm 1$ & 1.1 & $29 \pm 3$ & 0.7 & $\begin{array}{l}0.4 \\
0.4\end{array}$ & $\begin{array}{l}0.0 \\
8.0\end{array}$ & \\
\hline & & 1070 & 35 & 39 & $25 \pm 1$ & 0.6 & $33 \pm 3$ & 0.8 & -0.2 & 9.0 & 1.0 \\
\hline 9 & 1160 & 1160 & $4 \mathrm{hr}$ & 34 & $67 \pm 10$ & 2.0 & $28 \pm 6$ & 0.8 & 1.2 & 9.0 & \\
\hline & & 1090 & 4 & 35 & & & $33 \pm 3$ & 0.9 & & & \\
\hline & & 1080 & 5 & 35 & $59 \pm 17$ & 1.7 & $26 \pm 2$ & 0.7 & 1.0 & & \\
\hline & & 1120 & 15 & 39 & $44 \pm 4$ & 1.1 & $31 \pm 3$ & 0.8 & 0.3 & 8.0 & \\
\hline & & 1450 & 33 & 39 & $56 \pm 6$ & 1.4 & $39 \pm 3$ & 1.0 & 0.4 & 13.0 & 11.1 \\
\hline 10 & 1070 & 1025 & 3 & 36 & & & $37 \pm 3$ & 1.0 & & & \\
\hline & & 1000 & 4 & 36 & $35 \pm 7$ & 1.0 & $32 \pm 1$ & 1.1 & -0.1 & 9.0 & \\
\hline & & 1010 & 14 & 39 & $26 \pm 3$ & 0.7 & $31 \pm 5$ & 0.8 & -0.1 & 6.0 & \\
\hline 11 & 1980 & 1980 & $8 \mathrm{hr}$ & 42 & $107 \pm 14$ & 2.5 & $50 \pm 5$ & 1.2 & 1.3 & 9.0 & \\
\hline 14 & & 2020 & 9 & 42 & $63 \pm 8$ & 1.5 & $47 \pm 6$ & 1.1 & 0.4 & 12.0 & \\
\hline 12 & 1320 & 1320 & $6 \mathrm{hr}$ & 40 & $49 \pm 8$ & 1.2 & $31 \pm 2$ & 0.8 & 0.4 & 8.0 & \\
\hline & & 1275 & 1 & 40 & $29 \pm 8$ & 0.7 & $31 \pm 2$ & 0.8 & -0.1 & 7.0 & \\
\hline & & 1290 & 19 & 41 & $26 \pm 3$ & 0.7 & $35 \pm 4$ & 1.7 & -0.5 & 10.0 & \\
\hline 13 & 1440 & 1440 & $6 \mathrm{hr}$ & 40 & $41 \pm 7$ & 1.0 & $33 \pm 5$ & 0.8 & 0.2 & 6.0 & \\
\hline 20 & . & 1320 & 1 & 40 & $42 \pm 10$ & 1.0 & $30 \pm 2$ & 0.8 & $0 . \overline{2}$ & 9.0 & \\
\hline & & 1250 & 6 & 40 & $55 \pm 15$ & 1.4 & $36 \pm 6$ & 0.9 & 0.5 & 13.0 & \\
\hline & & 1420 & 19 & 41 & $40 \pm 4$ & 1.0 & $41 \pm 4$ & 1.0 & 0.0 & 9.0 & \\
\hline 14 & 1110 & 1040 & 1 & 34 & $35 \pm 3$ & 1.0 & $23 \pm 6$ & 0.7 & 0.4 & 11.0 & \\
\hline 15 & 2070 & 2080 & 2 & 44 & $79 \pm 11$ & 1.8 & $54 \pm 7$ & 1.2 & 0.6 & 19.0 & \\
\hline & & 2130 & 9 & 45 & $69 \pm 13$ & 1.5 & $52 \pm 4$ & 1.2 & 0.3 & 21.0 & \\
\hline 16 & 2200 & 2200 & 1 & 43 & $85 \pm 10$ & 2.0 & $36 \pm 3$ & 0.8 & 1.2 & 18.0 & \\
\hline 17 & 1820 & 1820 & $4 \mathrm{hr}$ & 44 & $74 \pm 10$ & 1.7 & $42 \pm 12$ & 1.0 & 0.7 & 24.0 & 6.0 \\
\hline & & 1790 & 1 & 44 & $49 \pm 3$ & 1.1 & $51 \pm 6$ & 1.2 & -0.1 & 11.0 & \\
\hline & & 1960 & 11 & 45 & $47 \pm 9$ & 1.0 & $57 \pm 7$ & 1.3 & -0.3 & 22.0 & \\
\hline 18 & 2500 & 2500 & 1 & 47 & $150 \pm 8$ & 3.2 & $60 \pm 1$ & 1.3 & 1.9 & 13.0 & \\
\hline & & 2480 & 2 & 47 & $134 \pm 18$ & 2.9 & $63 \pm 7$ & 1.3 & 1.6 & 15.0 & -6.0 \\
\hline & & 2480 & 3 & 47 & $111 \pm 11$ & 2.4 & $63 \pm 8$ & 1.3 & 1.1 & 24.0 & -1.8 \\
\hline & & 2400 & 6 & 48 & $119 \pm 17$ & 2.5 & $63 \pm 13$ & 1.3 & 1.2 & & \\
\hline 19 & 1474 & 1460 & 1 & 41 & $74 \pm 2$ & 1.8 & $36 \pm 2$ & 0.9 & 0.9 & 16.0 & \\
\hline & & 1420 & 2 & 41 & $40 \pm 4$ & 1.0 & $35 \pm 8$ & 0.9 & 0.1 & 8.0 & \\
\hline & & 1440 & 7 & 41 & $52 \pm 5$ & 1.3 & $43 \pm 4$ & 1.0 & 0.3 & 7.0 & \\
\hline & & 2120 & 29 & 46 & $55 \pm 7$ & 1.2 & $53 \pm 3$ & 1.2 & 0.0 & 22.0 & \\
\hline 20 & 2120 & 2100 & 1 & 44 & $74+8$ & 1.7 & $50 \pm 6$ & 1.1 & 0.4 & 15.0 & \\
\hline & & 2100 & 2 & 44 & $47 \pm 7$ & 1.1 & $41 \pm 2$ & 0.9 & 0.2 & 10.0 & \\
\hline & & 2040 & 7 & 44 & $66 \pm 7$ & 1.5 & $46 \pm 4$ & 1.0 & 0.5 & 16.0 & \\
\hline 21 & 1880 & 1880 & $2 \mathrm{hr}$ & 42 & $53 \pm 13$ & 1.3 & $53 \pm 6$ & 1.3 & 0.0 & 13.0 & \\
\hline & & 1780 & 4 & 42 & $55 \pm 5$ & 1.3 & $41 \pm 8$ & 1.0 & 0.3 & 17.0 & \\
\hline 22 & 1800 & 1800 & $2 \mathrm{hr}$ & 44 & $96 \pm 10$ & 2.2 & $65 \pm 5$ & 1.5 & 0.7 & 19.0 & \\
\hline & & 1840 & 3 & 44 & $60 \pm 15$ & 1.4 & & & & 24.0 & \\
\hline 23 & 1980 & 1980 & $4 \mathrm{hr}$ & 45 & $40 \pm 3$ & 0.9 & $42 \pm 5$ & 0.9 & 0.0 & 13.0 & \\
\hline 24 & 1660 & 1660 & $4 \mathrm{hr}$ & 43 & $50 \pm 6$ & 1.2 & $39 \pm 2$ & 0.9 & 0.3 & 19.0 & \\
\hline & & 1680 & 3 & 43 & $38 \pm 0$ & 1.1 & $40 \pm 7$ & 0.9 & 0.2 & 9.0 & \\
\hline 25 & 2050 & 2000 & 1 & 45 & $125 \pm 12$ & 2.8 & $55 \pm 3$ & 1.2 & 1.6 & 7.0 & \\
\hline & & 2000 & 2 & 45 & $68 \pm 3$ & 1.5 & $63 \pm 8$ & 1.4 & 0.1 & 10.0 & \\
\hline & & 1940 & 4 & 45 & $111 \pm 19$ & 2.5 & $82 \pm 14$ & 1.8 & 0.7 & & 6.7 \\
\hline 26 & 1390 & 1220 & 13 & 40 & $32 \pm 4$ & 0.8 & $33 \pm 7$ & 0.8 & 0.0 & 8.0 & 3.9 \\
\hline & & 1530 & 32 & 42 & $50 \pm 8$ & 1.2 & $31 \pm 2$ & 0.7 & 0.5 & 12.0 & \\
\hline
\end{tabular}

${ }^{1}$ Mean $\pm \mathrm{SE}$. 
ence in FRC was noted after $30 \mathrm{sec}$ of rebreathing, indicating that mixing had occurred by that time. Other considerations suggesting that mixing occurred in the time period covered by the test are: (1) Nitrogen washout analysis indicates that in most cases the lungs are washed out in $30 \mathrm{sec}$. (2) FRC values in this study are in close agreement with the results of others $[5,13]$ one of whom used a rebreathing method [5]. (3) Another indication of the validity of the method was the constancy of the helium FRC with time as it was approached by the TGV. A systematic error in FRC determination would not give this result. (4) A series of tests were carried out with the bag and mask in which nitrogen concentration in the bag was monitored. Infants were then allowed to breathe the helium-oxygen mixture, and the time and number of breaths required to reach a nitrogen plateau were determined. Infants who breathed regularly obtained equilibrium within

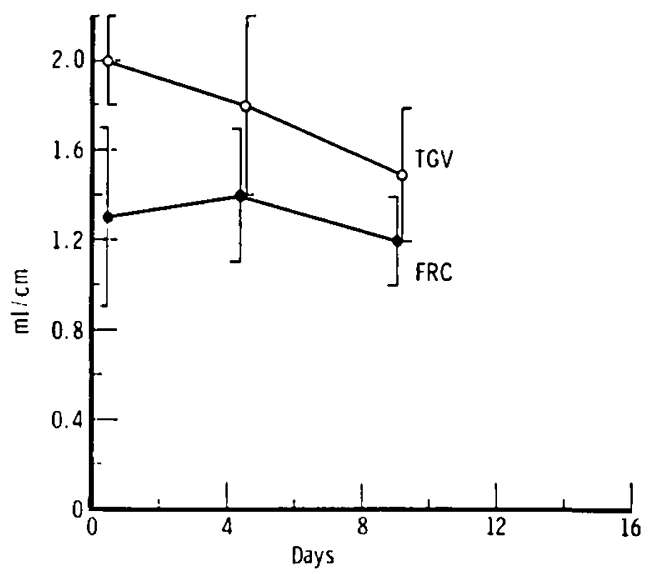

Fig. 1. TGV and FRC with respect to age after birth in infants with birth weights over $1750 \mathrm{~g}$.

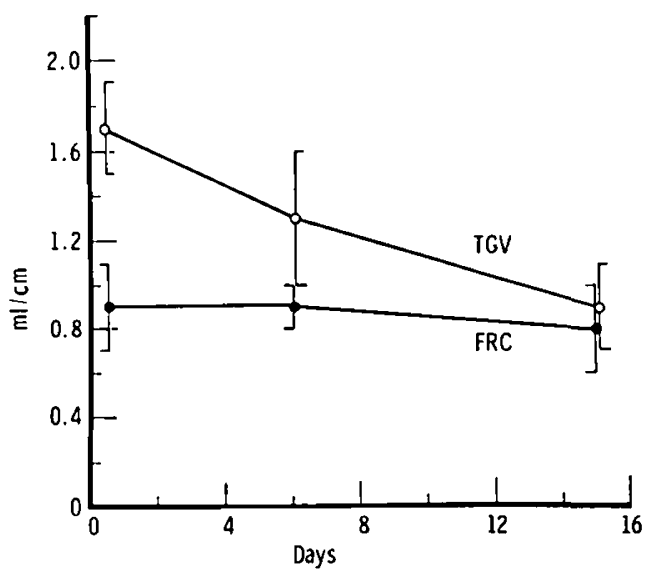

Fig. 2. TGV and FRC with respect to age after birth in infants with birth weights under $1750 \mathrm{~g}$.

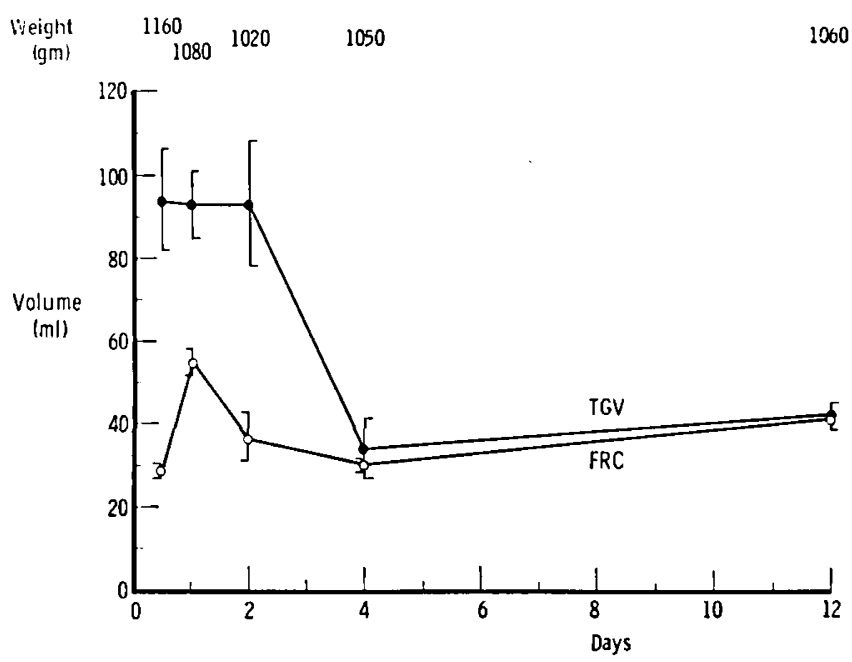

Fig. 3. Example of a small premature infant with trapped gas for 4 days.

Weight
(gm) $\quad 1160 \stackrel{1090}{1080} \quad 1120 \quad 1450$

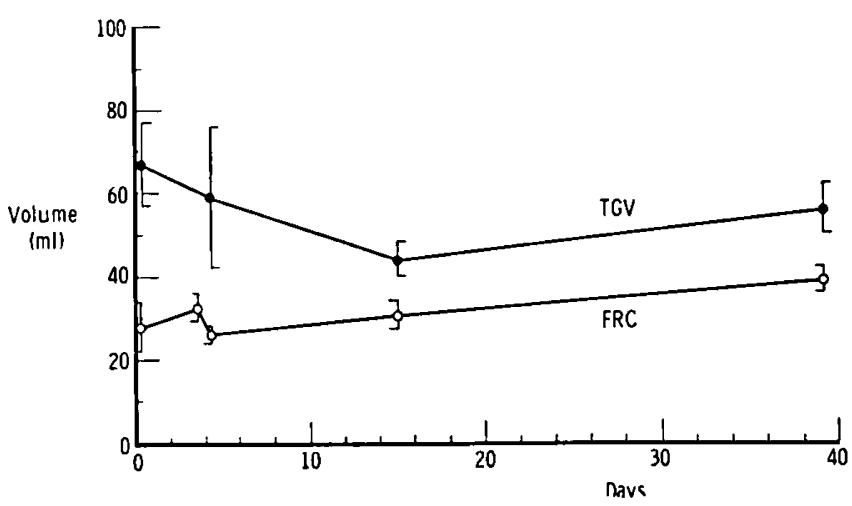

Fig. 4. Premature infant with trapped gas for at least 40 days.

$20 \mathrm{sec}$. In cases with apneic pauses, equilibrium was reached within 30 breaths.

\section{Results}

Serial values for TGV, FRC, and volume of trapped gas are presented in Table $I$. The results are expressed both in milliliters and in milliliters per centimeter of body length so that infants can be compared with each other. The FRC plotted against length indicated a curve (in agreement with the regression line of Cook et al. [6]), and on this basis the subjects were divided into two groups, those above and those below $1750 \mathrm{~g}$ birth weight (Figs. I and 2). The average FRC values between these two groups were statistically different at all ages studied. 
Table II. Nitrogen washout data

\begin{tabular}{|c|c|c|c|c|c|c|c|c|c|c|c|c|c|c|}
\hline Case & $\begin{array}{c}\text { Birth } \\
\text { weight, } \\
\text { g }\end{array}$ & $\begin{array}{c}\text { Study } \\
\text { weight, } \\
\text { B }\end{array}$ & $\begin{array}{l}\text { Age, } \\
\text { days }\end{array}$ & $\dot{V}_{A_{1}}{ }^{1} / L_{1}$ & $\dot{\mathrm{V}}_{\mathbf{A}_{2}}{ }^{1 / L_{1}}$ & $\begin{array}{l}\dot{V}_{A_{1}{ }^{2}} \\
\dot{v_{T}} A_{T}\end{array}$ & $\begin{array}{l}\dot{\mathrm{V}}_{\mathrm{A}_{2}{ }^{2} /} \\
\dot{\mathrm{V}} \mathrm{A}_{T}\end{array}$ & $L_{1}{ }^{3} / L_{T}$ & $\mathrm{~L}_{2}{ }^{1} / L_{\mathrm{T}}$ & $\begin{array}{c}\text { Actual } \\
\text { breath } \\
\text { no. }\end{array}$ & $\begin{array}{c}\text { Ideal } \\
\text { breath } \\
\text { no. }\end{array}$ & $\begin{array}{c}\text { Clear } \\
\text { ance } \\
\text { delay, } \\
\%\end{array}$ & $\begin{array}{l}\text { TGV- } \\
\text { FRC, } \\
\mathrm{ml}\end{array}$ & $\begin{array}{l}\text { Trapped gas, } \\
\mathrm{ml} / \mathrm{cm}\end{array}$ \\
\hline \multirow[t]{4}{*}{7} & 1160 & 1160 & $8 \mathrm{hr}$ & 2.5 & & 1.00 & & 1.00 & & 16.4 & 16.4 & 0 & 65 & 1.7 \\
\hline & & 1050 & 4 & 37.1 & 4.3 & 0.35 & 0.65 & 0.06 & 0.94 & 16.2 & 13.1 & 23 & 4 & 0.1 \\
\hline & & 1160 & 9 & 30.0 & 2.5 & 0.43 & 0.57 & 0.06 & 0.94 & 17.6 & 14.3 & 24 & & \\
\hline & & 1060 & 12 & 6.6 & 2.6 & 0.47 & 0.53 & 0.26 & 0.74 & 17.1 & 15.5 & 11 & 1 & 0 \\
\hline \multirow[t]{3}{*}{8} & 1030 & 1000 & 1 & 8.1 & 2.2 & 0.27 & 0.73 & 0.09 & 0.91 & 15.9 & 15.6 & 2 & 28 & 0.8 \\
\hline & & 860 & 8 & 55.3 & 2.8 & 0.21 & 0.79 & 0.01 & 0.99 & 15.0 & 13.5 & 11 & & \\
\hline & & 1070 & 35 & 27.6 & 4.9 & 0.43 & 0.57 & 0.12 & 0.88 & 7.9 & 5.2 & 52 & -8 & -0.2 \\
\hline \multirow[t]{2}{*}{9} & 1160 & 1080 & 7 & 9.2 & 1.8 & 0.03 & 0.97 & 0.01 & 0.99 & 12.1 & 8.1 & 48 & & \\
\hline & & 1120 & 15 & 7.7 & & 1.00 & & 1.00 & & 11.0 & 11.0 & 0 & 8 & 0.3 \\
\hline 10 & 1070 & 1000 & 14 & 25.0 & 6.9 & 0.46 & 0.54 & 0.21 & 0.79 & 10.1 & 8.1 & 26 & -5 & -0.1 \\
\hline 11 & 1980 & 1980 & $8 \mathrm{hr}$ & 7.3 & & 1.00 & & 1.00 & & 11.9 & 11.9 & 0 & 57 & 1.3 \\
\hline 12 & 1320 & 1320 & $6 \mathrm{hr}$ & 5.4 & & 1.00 & & 1.00 & & 11.6 & 11.6 & 0 & 18 & 0.4 \\
\hline \multirow[t]{2}{*}{13} & 1440 & 1440 & $6 \mathrm{hr}$ & 27.7 & 6.9 & 0.22 & 0.78 & 0.06 & 0.94 & 14.2 & 12.8 & 11 & 8 & 0.4 \\
\hline & & 1250 & 6 & 15.0 & 5.5 & 0.74 & 0.26 & 0.46 & 0.54 & 8.3 & 7.0 & 18 & 19 & 0.5 \\
\hline 14 & 1110 & 1040 & 1 & 55.3 & 2.3 & 0.18 & 0.82 & 0.01 & 0.99 & 31.8 & 26.3 & 21 & 12 & 0.4 \\
\hline 15 & 2070 & 2080 & 2 & 13.8 & 5.1 & 0.37 & 0.63 & 0.18 & 0.82 & 6.3 & 6.0 & 5 & 25 & 0.6 \\
\hline 17 & 1820 & 1820 & $4 \mathrm{hr}$ & 3.4 & & 1.00 & & 1.00 & & 11.0 & 11.0 & 0 & 32 & 0.7 \\
\hline 18 & 2500 & 2500 & 1 & 4.2 & & 1.00 & & 1.00 & & 14.9 & 14.9 & 0 & 90 & 1.9 \\
\hline 19 & 1474 & 1500 & 1 & 31.4 & 2.7 & 0.34 & 0.66 & 0.04 & 0.96 & 14.3 & 11.6 & 23 & 38 & 0.9 \\
\hline \multirow[t]{3}{*}{20} & 2120 & 2100 & 1 & 23.0 & 1.3 & 0.54 & 0.46 & 0.06 & 0.94 & 23.8 & 23.8 & 0 & 24 & 0.4 \\
\hline & & 2160 & 12 & 6.0 & & 1.00 & & 1.00 & & 19.2 & 19.2 & 0 & & 0 \\
\hline & & 2160 & 12 & 30.7 & 5.3 & 0.52 & 0.48 & 0.16 & 0.84 & 15.2 & 11.1 & 27 & & 0 \\
\hline 24 & 1660 & 1660 & $4 \mathrm{hr}$ & 46.0 & 5.8 & 0.35 & 0.65 & 0.07 & 0.93 & 7.5 & 6.7 & 12 & 11 & 0.3 \\
\hline \multirow[t]{3}{*}{25} & 2050 & 2000 & 1 & 39.5 & 3.5 & 0.26 & 0.74 & 0.03 & 0.97 & 10.1 & 6.0 & 69 & 70 & 1.6 \\
\hline & & 2000 & 2 & 34.3 & 8.2 & 0.26 & 0.23 & 0.03 & 0.10 & 22.1 & 6.8 & 220 & 5 & $1.1^{4}$ \\
\hline & & 1940 & 4 & 30.7 & 2.0 & 0.28 & 0.72 & 0.02 & 0.98 & 22.4 & 17.9 & 25 & 29 & 0.7 \\
\hline 26 & 1390 & 1200 & 13 & 2.4 & & 1.00 & & 1.00 & & 12.8 & 12.8 & 0 & -1 & 0 Post HMD \\
\hline
\end{tabular}

$1 \dot{\mathrm{V}}_{\mathrm{A}} / \mathrm{L}=$ alveolar ventilation, $\mathrm{ml}$ per min, per unit of lung volume, $\mathrm{ml}$.

$2 \dot{V} A_{1} / \dot{V} A_{T}=$ fraction of alveolar ventilation in most rapidly ventilated space.

${ }^{3} \mathrm{~L}_{1} / \mathrm{L}_{\mathrm{T}}=$ fraction of lung volume in most rapidly ventilated space.

- $\mathrm{VA}_{3} / \mathrm{L}_{2}=2.2 \mathrm{VA}_{3} / \mathrm{V}_{\mathrm{T}}=0.51 \mathrm{~L}_{3} / \mathrm{L}_{\mathrm{T}}=0.87$.

In the first $24 \mathrm{hr}$ of life, mean TGV for the infants over $1750 \mathrm{~g}$ birth weight was $2.0 \pm 0.7 \mathrm{ml} / \mathrm{cm}$ and FRC $1.3 \pm 0.4 \mathrm{ml} / \mathrm{cm}$, a significant difference $(P=$ $<0.01)$. By days $3-6$ the mean value of TGV for these infants was $1.8 \pm 0.6 \mathrm{ml} / \mathrm{cm}$ and mean FRC was $1.4 \pm$ $0.3 \mathrm{ml} / \mathrm{cm}$, not a significant difference (Fig. 2). Infants under $1750 \mathrm{~g}$ birth weight had a mean TGV of $1.7 \pm$ $0.2 \mathrm{ml} / \mathrm{cm}$ and a mean FRC of $0.9 \pm 0.2 \mathrm{ml} / \mathrm{cm}$, significant at $P=<0.01$. By days $12-19$ of life the mean TGV of the smaller infants was $0.9 \pm 0.2 \mathrm{ml} / \mathrm{cm}$ and FRC was $0.8 \pm 0.2 \mathrm{ml} / \mathrm{cm}$, not a significant difference (Fig. 2). In an individual subject, the rate of disappearance of trapped gas was variable and did not appear to be related to birth weight or age (Table I and Figs. 3 and 4).

Repeated nitrogen washouts demonstrated that with few exceptions the infants had uniformly ventilated lungs even when gas trapping was present (Table II). The urinary alveolar nitrogen gradients were all within normal limits (one slightly elevated to $11.1 \mathrm{~mm}$ $\mathrm{Hg}$ ), confirming the presence of normal distribution of ventilation-perfusion in these subjects (Table I). The magnitude of the $\mathrm{UAD}_{\mathrm{N}_{2}}$ did not correlate with the amount of trapped gas. Negative $\mathrm{uAD}_{\mathrm{N}_{2}}$ were noted occasionally; there is currently no explanation for this.

\section{Discussion}

This study confirms the observations of others $[13,15]$ in demonstrating gas trapping in the lungs of premature infants. Trapped gas is present from birth and persists for a variable period of time, in some cases as long as 40 days. Disappearance of trapped gas thus explains the fall in TGV noted in this and previous studies [16], as the TGV eventually approached the FRC. In fact, the FRC is generally constant for each infant over the period of the study. Analysis of nitrogen washout curves determined concurrently with the 
volume measurements indicates that even in the presence of gas trapping the lungs are uniformly ventilated. No slow space is evident, and the pulmonary clearance delay is minimal. Normally ventilated lungs in healthy infants and adults usually have VA/L (alveolar ventilation (liters per minute)/lung volume (liters)) ratios over $1-3$. The poorly ventilated space of adults or children with emphysema or cystic fibrosis has a $\dot{V A} / L$ ratio of under 1 . Thus, it appears that the areas of trapped gas are completely nonventilated or receive so little ventilation as to be undetectable on nitrogen washout. The normal $\mathrm{uAD}_{\mathrm{N}_{2}}$ indicates that these pockets are not only poorly ventilated but poorly perfused or even unperfused. Absence of roentgenographic evidence of pneumothorax, cysts, and blebs suggests that the gas is trapped in alveoli.

The disappearance of trapped gas within several days in some instances and its persistence in others for a considerable time suggest that perhaps two factors are operating. First, the lungs of certain mammalian fetuses are known to be liquid-filled in utero [10]. Immediately after birth at least some of the fluid must be replaced with air. Gas trapping may occur at this time in the fluid itself in the form of bubbles, or in alveoli distal to the fluid. Ability to form an alveolar lining layer would thus be a prerequisite if gas was trapped in the bubbles, because bubbles without surfactin would be unstable. Resorption of lung fluid would result in disappearance of trapped gas. It is unlikely that this explanation would apply to gas trapping for the prolonged periods noted in this study. A second explanation for prolonged gas trapping is provided by the work of Burnard et al. [4]. They showed that the airways of immature infants are very compliant, much like the chest wall. These factors tend to favor bronchiolar collapse during expiration with resulting gas trapping. This state may persist for prolonged periods of time until the bronchiolar structures become stiffer and less subject to collapse. Infants would preferentially ventilate only alveoli with bronchioles which remained patent as this would require least work. However, in all instances the gas must be completely trapped and the areas nonperfused as indicated by normal $\mathrm{uAD} \mathrm{N}_{2}$ and nitrogen washout. The disappearance of the poorly perfused trapped areas could in some instances result in atelectasis with little effect on over-all $\dot{\mathrm{V} A} / \dot{\mathrm{Q}}$.

Multiple factors are involved in the development of trapped gas and the course of its resolution. These include the development of the alveolar lining, tissue resistance, airway resistance, lung and chest wall com- pliance, and the ability of a given infant to perform the work of breathing. Variation in the rates of maturation of the systems involved may affect the infant's ability to trap gas.

The possibility that the gas trapping demonstrated herein was merely a result of methodology was considered. This conclusion is deemed unlikely because of the obvious decrease in chest volume with time noted by direct observation (decrease in TGV) and the constancy of FRG with time.

\section{Summary}

Gas trapping has been shown to occur in premature infants in the process of adaptation to extrauterine life. In the presence of gas trapping nearly perfect distribution of ventilation occurs, indicating that the gas trapped areas are poorly ventilated or not ventilated at all.

\section{References and Notes}

1. Auld, P. A. M., Nelson, N. M., Cherry, R. B., Rudolph, A. J., AND Smith, C. A.: Measurement of thoracic gas volume in the newborn infant. J. Clin. Invest., $42: 476$ (1963).

2. Briscoe, W. A.: Lung volumes. In: W. O. Fenn and H. Rahn: Handbook of Physiology, Sect. 3, Respiration, Vol. II. (American Physiological Society, Washington, D.C., 1965).

3. Briscoe, W. A., AND Cournand, A.: Uneven ventilation of normal and diseased lungs studied by an open-circuit method. J. Appl. Physiol., 14: 284 (1959).

4. Burnard, E. D., Grattan-Smith, P., Picton-tVarlow, C. G., and Grauaug, A.: Pulmonary insufficiency in prematurity. Aust. Paediat. J., 1: 12 (1965).

5. Chu, J., Clements, J. A., Cotton, E. K., Klaus, M. H., Sweet, A. Y., AND Tooley, W. H.: Neonatal pulmonary ischemia. Part I. Clinical and physiological studies. Pediatrics, 40: 709 (1967).

6. Cook, C. D., Helliesen, P. J., and Agathon, S.: Relation between mechanics of respiration, lung size and body size from birth to young adulthood. J. Appl. Physiol., 13: 349 (1958).

7. Dubois, A. B., Botelho, S. Y., Bedell, G. N., Marshall, R., and Comroe, J. H., JR.: A rapid plethysmographic method for measuring thoracic gas volume; a comparison with a nitrogen washout method for measuring functional residual capacity in normal subjects. J. Clin. Invest., 35: 322 (1956).

8. Farhi, L. E., Edward, A. W. T., ANd Homma, T.: Determination of dissolved $\mathrm{N}_{2}$ in blood by gas chromatography and (a - A) $\mathrm{N}_{2}$ difference. J. Appl. Physiol., 18: 97 (1963).

9. Fowler, W. S., Cornish, E. R., Jr., and KetY, S. S.: Lung function studies. VIII. Analysis of alveolar ventilation by pulmonary $\mathrm{N}_{2}$ clearance curves. J. Clin. Invest., 31: 40 (1952).

10. Fujiwara, T., Adams, F. H., ANd Scudder, A.: Fetal lamb amniotic fluid: Relationship of lipid composition to surface tension. J. Pcdiat., 65: 824 (1964).

11. Krauss, A. N., And Auld, P. A. M.: Ventilation perfusion ab- 
normalities in the premature infant: Triple gradient. Pediat. Res., 3: 255 (1969).

12. Lewis, B. M., LiN, T. H., NoE, F. E., ANd HAYFord-Welsing, E. J.: The measurement of pulmonary diffusing capacity for carbon monoxide by rebreathing method. J. Clin. Invest., 38: 2073 (1959).

13. Nelson, N. M., Prod'Hom, L. S., Cherry, R. B., Lipsitz, P. J., AND SMirr, C. A.: Pulmonary function in the newborn infant. V. Trapped gas in the normal infant's lung. J. Clin. Invest., 42: 1850 (1963).

14. Strang, L. B., and McGrath, M. W.: Alveolar ventilation in normal newborn infants studied by air wash-in after oxygen breathing. Clin. Sci., 23: 129 (1962).

15. Thibenult, D. W., Poblettre, E., And Auld, P. A. M.: Alveolararterial $\mathrm{O}_{2}$ and $\mathrm{CO}_{2}$ differences and their relation to lung volume in the newborn. Pediatrics, 41: 574 (1968).

16. Thibeault, D. W., Wong, M. M., And Auld, P. A. M.: Tho- racic gas volume changes in premature infants. Pediatrics, 40: 403 (1967).

17. Monaghan Company, Denver, Colo.

18. Warren E. Collins, Braintree, Mass.

19. Instrumentation Laboratory, Boston, Mass.

20. Med-Science Electronics, St. Louis, Mo.

21. This study was performed within the spirit of the Declara. tion of Helsinki.

22. Supported by Public Health Service Research Grant no. HD. 02644. Dr. Auld holds an Investigatorship of the Health Research Council of New York under Contract no. I-236.

23. Requests for reprints should be addressed to: A. N. Krauss, Department of Pediatrics, Cornell University Medical College, New York, N. Y. 10021 (USA).

24. Dr. Auld's present address: 525 E. 68th St., New York, N. Y. 10021 (USA).

25. Accepted for publication April 17, 1970. 